\title{
Pharmacological modulation of MRAP2 protein on melanocortin receptors in the sea lamprey
}

\author{
Ming Zhu, Bingxin Xu, Meng Wang, Shangyun Liu, Yue Zhang and Chao Zhang \\ Translational Medical Center for Stem Cell Therapy and Institute for Regenerative Medicine, Shanghai East Hospital, Shanghai Key Laboratory of Signaling \\ and Disease Research, School of Life Sciences and Technology, Tongji University, Shanghai, China
}

Correspondence should be addressed to C Zhang: zhangchao@tongji.edu.cn

\begin{abstract}
Melanocortin receptors (MCRs) and their accessory proteins (MRAPs) evolutionarily first appear in the genome of sea lamprey. The most ancient melanocortin system consists of only two melanocortin receptors (SIMCa and sIMCb) and one MRAP2 (sIMRAP2) protein, but the physiological roles have not been fully explored in this primitive species. Here, we synthesize and characterize the pharmacological features of sIMRAP2 protein on two sIMCRs. Our results show that the sIMRAP2 protein lacks the long carboxyl terminus; it directly interacts and decreases the surface expression but enhances the $\alpha-\mathrm{MSH}$-induced agonism of sIMCa and sIMCb. In comparison with higher organisms such as elephant shark and zebrafish, we also demonstrate the constantly evolving regulatory function of the carboxyl terminus of MRAP2 protein, the unique antiparallel topology of sIMRAP2 dimer and the homo- and hetero-dimerization of two sIMCRs. This study elucidates the presence and modulation of melanocortin receptor by the accessory protein of the agnathans for the first time, which provides a better insight of the melanocortin system in ancient species of chordates.
\end{abstract}

\section{Key Words}

- melanocortin 2 receptor accessory protein 2

- melanocortin receptors

- sea lamprey

\section{Introduction}

The melanocortin receptors (MCRs) belong to $\alpha$ group of rhodopsin G-protein-coupled receptors. Mammalian MCRs consist of five subtypes, generally referred to as MC1R, MC2R, MC3R, MC4R and MC5R. A widely reported function of MC1R is for pigmentation, MC2R for adrenocortical steroidogenesis, MC3R for energy homeostasis, MC4R for appetite control and MC5R for exocrine secretion (1). Four pro-opiomelanocortin (POMC)-derived natural agonists $(\alpha-, \beta-, \gamma$-MSH and ACTH) and two antagonists (Agouti and AgRP) exist for the modulation of MCR signaling $(1,2,3,4)$. The melanocortin receptors have been reported to form homo- and heterodimers and could result in profound functional consequences $(5,6,7)$. Moreover, trafficking and signaling of the MCRs are endogenously regulated by melanocortin receptor accessory proteins (MRAPs) containing two single transmembrane proteins, named MRAP (MRAP1) and MRAP2 (8). MRAP1 functions as an antiparallel homodimer and is essential for the plasma membrane translocation and ACTH response of $\operatorname{MC} 2 \mathrm{R}(9,10)$. MRAP could also affect dimerization of melanocortin receptors. In fact, MRAP promotes dimerization of MC2R, but prevents MC5R from forming homodimers (11). MRAP2, found as a homologue of MRAP, could also form antiparallel homodimers and modulate all five melanocortin receptors $(12,13)$. Human MRAP2 shows some or no effect on suppressing MC4R signaling $(12,13)$. However, mouse MRAP2 is capable of sensitizing the $\alpha$-MSH-induced agonism of MC4R, and dysfunction of MRAP2 causes severe obesity syndrome (14). Two MRAP2 homologues exist in the zebrafish genome. MRAP2a stimulates somatic growth during larval development by inhibiting MC4R, while MRAP2b enhances ligand sensitivity of MC4R (c) 2019 The authors Published by Bioscientifica Ltd
This work is licensed under a Creative Commons Attribution-NonCommercial-NoDerivatives 4.0 elnternationab sicense ifica.com at 04/26/2023 10:00:13AM 
and regulate appetite and growth when feeding begins $(15,16)$.

The melanocortin system is present in phylum chordate, while the members (especially the melanocortin receptors) diverge among different species $(8,17,18)$. A tremendous amount of work has been done in elucidating the roles of the melanocortin system of Chondrichthyes and Osteichthyes (8). However, little attention has been paid to the most ancient fish species in the class of Cyclostomata. Lamprey (Lampetra japonicum) and hagfish (Myxini glutinosa) are the only known existing jawless vertebrates (19). The ancient ancestors of the melanocortin receptors are cloned from the river lamprey, named $\mathrm{MCa}$ and $\mathrm{MCb}$ (20). Upon second genomic duplication, MC1R, MC2R and MC5R form from MCa, while MC3R and MC4R form from $\mathrm{MCb}$ (21). However, Vastermark et al. suggest that MC2R and MC5R do not evolve from a common ancestor. Except for the ancient melanocortin receptors, an MRAP2-like but not MRAP1-like sequence has been identified in sea lamprey indicating MRAP2 is likely to be the ancestor of the MRAPs system (22). Compared to other species, the amino acid sequence of sea lamprey MRAP2 protein is very short because the carboxyl terminus of slMRAP2 is missing (23). More interestingly, no agonist or antagonist has been identified so far in the sea lamprey genome (22) and whether the ancient slMRAP2 could modulate slMCRs remains unknown.

In this study, we synthesize slMCa, slMCb and slMRAP2, and supplement wild-type slMRAP2 with the carboxyl terminus of elephant shark MRAP2, zebrafish MRAP2a or zebrafish MRAP2b, abbreviated as esMRAP2-C, zMRAP2a-C, zMRAP2b-C, respectively. The pharmacological modulation of the slMRAPs protein on slMCa and slMCb and the dimerization of slMRAP2 and slMCRs are then further examined. Our results demonstrate that the sIMRAP2 with a very short carboxyl terminus is fully functional in regulating slMCa or slMCb, and the dimerization event exists for the most ancient melanocortin receptors.

\section{Methods and materials}

\section{Sequences blast and alignment}

The accession numbers of all sequences in this study are given in Table 1. The National Center for Biotechnology Information (NCBI) tblastn was utilized to search the complete protein sequence of slMRAP2 and slMCa in the sea lamprey genomic database and alignment was performed using the software of DNAMAN.

\section{Plasmids and peptides}

slMRAP2, slMCa and slMCb were synthesized by Generay Biotechnology (Shanghai, China), sub-cloned into pc-DNA3.1(+) vector. The transmembrane (TM) domain of slMRAP2 was predicted from TMHMM (http://www. cbs.dtu.dk/services/TMHMM/). The N-terminal and TM domain of slMRAP2 was then reconstructed with the carboxyl terminus of elephant shark (Callorhinchus milii) MRAP2 (esMRAP2-C), zebrafish (Danio rerio) MRAP2a (zMRAP2a-C) or zebrafish (Danio rerio) MRAP2b (zMRAP2b-C), respectively. Both slMCa and slMCb plasmids carried 3HA tag and all of the MRAP2 plasmids carried V5, HA or 2Flag tag at the N terminus. For live cell imaging assay, slMRPA2, slMCa and slMCb were fused to

Table 1 Overview of accession numbers of sequences.

\begin{tabular}{l}
\hline Accession number \\
\hline ENSPMAT00000000587 \\
GL476894.1 \\
BN001505.1 \\
BN001506.1 \\
GL477446.1 \\
BK007095.1 \\
DQ213059.1 \\
DQ213060.1 \\
XM_007908433.1 \\
XM_001342887.6 \\
XM_005168521.3 \\
BR000855.1 \\
BR000856.1 \\
XM_007885593.1 \\
XM_007895520.1/LOC103179728 \\
XM_007895123.1
\end{tabular}

\begin{tabular}{l}
\hline Organism \\
\hline Petromyzon marinus \\
Petromyzon marinus \\
Petromyzon marinus \\
Petromyzon marinus \\
Petromyzon marinus \\
Petromyzon marinus \\
Lampetra fluviatilis \\
Lampetra fluviatilis \\
Callorhinchus milii \\
Danio rerio \\
Danio rerio \\
Callorhinchus milii \\
Callorhinchus milii \\
Callorhinchus milii \\
Callorhinchus milii \\
Callorhinchus milii
\end{tabular}

Description
MRAP2, exons 1 and 2
unplaced genomic scaffold_566
MCa, 5'-end
MCa, 3'-end
unplaced genomic scaffold_1118
MCb
MCa
MCb
MRAP2
MRAP2a
MRAP2b
MC1R, partial cds
MC2R, partial cds
MC3R
MC4R
MC5R


yellow fluorescent protein (YFP-F1/F2) fragments in the N terminus or $\mathrm{C}$ terminus, respectively (slMRAP2-YFP-F1/F2, YFP-F1/F2-slMRAP2, slMCa-YFP-F1/F2, slMCb-YFP-F1/F2). Human $\alpha$-MSH was purchased from GenScript Corporation Ltd (Nanjing, China) and human AgRP (83-139) were synthesized by Chinese Peptide LLC (Hangzhou, China).

\section{Cell culture and transfection}

HEK293T cells were maintained in high-glucose DMEM medium containing 10\% FBS and 1\% penicillin/ streptomycin. CHO cells were maintained in DMEM/F12 medium containing 5\% FBS and $1 \%$ penicillin/ streptomycin. Cells were transfected with indicated plasmids using ViaFect Transfection Reagent (Promega). Total plasmid concentration was kept identical for all transfections by the addition of empty pcDNA3.1 vector.

\section{Co-immunoprecipitation and Western blot}

HEK293T cells transiently co-transfected with slMCa or slMCb and four types of MRAP2 were incubated in lysis buffer $(0.75 \%$ Triton- $\mathrm{X}, 50 \mathrm{mM}$ Tris- $\mathrm{HCl} \mathrm{pH} 7.9$, $150 \mathrm{mM} \mathrm{NaCl}$ and proteinase inhibitor cocktail from Roche) for $1 \mathrm{~h}$ at $4^{\circ} \mathrm{C}$. Lysates were then centrifuged and the supernatants were incubated with anti-HA antibody (Abcam) overnight at $4^{\circ} \mathrm{C}$. Immune complexes were collected by adding Protein A/G Agarose beads (Beyotime Biotechnology, Suzhou, China) and rotated at $4^{\circ} \mathrm{C}$ for $4 \mathrm{~h}$. Beads were washed three times in lysis buffer and resuspended in loading buffer and boiled for $15 \mathrm{~min}$. Initial lysates and immunoprecipitation proteins were separated by SDS-PAGE on $12 \%$ polyacrylamide gels and the protein was then transferred onto PVDF membrane and then gently shaken in Tris-buffered saline and Tween (TBST) containing 5\% skim milk for $1 \mathrm{~h}$. The membrane was subsequently treated with primary mouse antibody against HA (1:5000, Abcam) at $4^{\circ} \mathrm{C}$ overnight. Finally, membranes were incubated with the secondary rabbit peroxidase (HRP)-conjugated antibody (Rockland, Limerick, PA, USA) at a dilution of 1:5000 for $2 \mathrm{~h}$ at room temperature and washed three times, followed by autoradiography and recording.

\section{cAMP assay}

HEK293T cells were plated in 24-well plates and the transient transfections with indicated plasmids were performed the next day. Cell transfection condition was divided into 16 groups: slMCa or slMCb was co-transfected with four types of MRAP2 at the ratio of 1:0, $1: 3$ and 1:6. Upon $24 \mathrm{~h}$ of transfection, cells were treated with different concentrations of $\alpha$-MSH in DMEM supplemented with $0.1 \%$ bovine serum albumin for $4 \mathrm{~h}$ at $37^{\circ} \mathrm{C}$. For the competition binding experiment, cell transfection condition was divided into 24 groups: slMCa or slMCb was co-transfected with four types of MRAP2 at the ratio of 1:0, 1:3 and 1:6. Cells were then treated with a fixed concentration of $\alpha-\mathrm{MSH}(2 \mathrm{nM})$ and different concentrations of AgRP in DMEM supplemented with $0.1 \%$ bovine serum albumin for $4 \mathrm{~h}$ at $37^{\circ} \mathrm{C}$. The cAMP level was measured as described before (24) using the DualGlo Luciferase Assay System (Promega). Luminescence was measured with a Spectramax M5 plate reader.

\section{Cell surface ELISA}

HEK293T cells were seeded onto poly-L-lysine-coated 12 -well plates at $10^{5}$ cells/well and transfected with indicated plasmid the next day. After $24 \mathrm{~h}$ of transfection, cells were washed with D-PBS three times, fixed with $4 \%$ polyformaldehyde for $20 \mathrm{~min}$ at room temperature, washed, blocked in D-PBS supplemented with $5 \%$ milk for $30 \mathrm{~min}$, incubated with 1:5000 anti-HA antibody at $37^{\circ} \mathrm{C}$ for $2 \mathrm{~h}$, and then washed three times for $5 \mathrm{~min}$ with D-PBS, incubated with 1:5000 secondary antibodies at $37^{\circ} \mathrm{C}$ for $1 \mathrm{~h}$. Then, cells were washed three times for 5 min with D-PBS and incubated with TMB solution (Beyotime Biotechnology, Suzhou, China) for 15-30 min. The reaction was terminated with $2 \mathrm{M}$ sulfuric acid, and then $200 \mu \mathrm{L}$ were transferred to a 96-well plate, and the absorbance was read at $450 \mathrm{~nm}$ on Spectramax M5 plate reader.

\section{Immunofluorescence}

$\mathrm{CHO}$ cells were transfected with indicated plasmid $48 \mathrm{~h}$ before the experiment on glass coverslips. Cells were fixed with $4 \%$ polyformaldehyde for $20 \mathrm{~min}$ at room temperature, washed, blocked in D-PBS supplemented with 5\% milk for $30 \mathrm{~min}$. Where noted, nuclei were counterstained with Hoechst $33342(3 \mu \mathrm{g} / \mathrm{mL})$ for $10 \mathrm{~min}$ at room temperature. A Zeiss confocal microscope (Jena, Germany) with $\times 60 / 1.3$ NA oil objective and Photometrics CoolSNAP ES camera were employed. Micrographs displayed in a group were exposed and processed identically.
This work is licensed under a Creative Commons Attribution-NonCommercial-NoDerivatives 4.0 elnternationad ticense ifica.com at 04/26/2023 10:00:13AM 


\section{Statistical analysis}

All experiments had been repeated three times in separate experiments. Data were shown as the mean \pm s.E.M. and analyzed using GraphPad Prism v7.0. cAMP assays were analyzed by two-way ANOVA with Tukey post-test. The Student's t-test was adopted to analyze the significance between two independent groups. $P$ values $<0.05$ were considered statistically significant. ${ }^{*} P<0.05,{ }^{* *} P<0.01$, ${ }^{* * *} P<0.001$.

\section{Results}

\section{Characterization of MRAP2 and MCRs in the sea lamprey}

Through the NCBI and ensemble database, we found complete slMCb and partial slMCa and slMRAP2 coding sequences (Table 1). The complete slMCa protein sequence was identified with the tblastn tool of the NCBI database. The slMCa and slMCb sequences were aligned to corresponding MCRs of river lamprey and elephant shark. As shown (Fig. 1A and B), slMCa exhibited the highest identity, $94.78 \%$ to rlMCa subtypes, while the identity to the esMC1R and esMC2R was lower, 42.03\% and $41.74 \%$, respectively. Similarly, slMCb showed the highest identity to rlMCb subtypes (88.74\%) and lower identity to esMC3R (55.50\%), esMC4R (57.91\%) and esMC5R $(54.96 \%)$. The same approach was utilized to search the complete sIMRAP2 sequence, but failed to identify the conserved carboxyl terminus such as those of zebrafish or mammalian MRAP2. Interestingly, we found a stop codon behind the partial sequences near the transmembrane domain of slMRAP2 (Fig. 1C).

\section{The interaction of sea lamprey MRAP2s with MCRs}

In order to examine the influences of the carboxyl terminus of MRAP2 protein on MCR signaling, we constructed four types of MRAP2s: the short carboxyl terminus of slMRAP2 was replaced by the full carboxyl terminus of elephant shark MRAP2 (esMRAP2-C), zebrafish MRAP2a (zMRAP2a-C) or zebrafish MRAP2b (zMRAP2b-C), respectively (Fig. 2I). Co-immunoprecipitation (Co-IP) was applied to monitor the protein interactions of MRAP2s with slMCRs. Results showed that slMRAP2 could interact with either slMCa or slMCb by forming a tight protein complex (Fig. 2A and B). Similarly, esMRAP2-C, zMRAP2a-C and zMRAP2b-C could also interact with slMCa or slMCb (Fig. 2C, D, E, F, G and
H). These data suggested that slMRAP2 might be the real functional accessory protein with the potential ability to interact and modulate the signaling of slMCa and slMCb. Interestingly, additional bands were detected in Fig. 2C, D, E and F but not in Fig. $2 \mathrm{~A}$ and $\mathrm{B}$ indicating that the carboxyl terminus should be required for the glycosylation of MRAP2 protein, but not for the interaction with MCRs.

\section{Pharmacological modulation of MRAP2s on sIMCa and sIMCb signaling}

To investigate the impact of four MRAP2s on slMCa and slMCb signaling, the cAMP level was detected with pCreluciferase reporter assay. Results showed that slMRAP2 could enhance the $\alpha-\mathrm{MSH}$ response of slMCa or $\mathrm{slMCb}$ (Fig. 3A and B). A similar trend was seen in the presence of esMRAP2-C (Fig. 3C and D) or zMRAP2b-C (Fig. 3G and H). The zMRAP2a-C, however, sensitized the slMCb signaling in a similar way as slMRAP2 (Fig. 3F) but suppressed the response of slMCa (Fig. 3E). Besides, all the four MRAP2s did not significantly change the $\mathrm{EC}_{50}$ of slMCa and slMCb for $\alpha$-MSH (Table 2).

\section{Effects of MRAP2s on surface expression of sIMCa and sIMCb}

We further explored whether MRAP2 affected MCR signaling by altering the cell surface expression. ELISA assays were employed to monitor the surface level of slMCa and slMCb in the presence of certain ratios of MRAP2 protein. As shown (Fig. 4A, C, E and G), surface expression of slMCa dramatically decreased in the presence of MRAP2s. zMRAP2b-C did not decrease slMCa surface expression at the ratio of $1: 3$ (Fig. 4G). slMCb surface expression was not suppressed by slMRAP2 as much as slMCa (Fig. 4B). However, the surface level of slMCb significantly decreased when slMRAP2 carboxyl terminus was replaced by esMRAP2 (Fig. 4D) or zMRAP2a carboxyl terminus (Fig. 4F), but not with zMRAP2b-C (Fig. 4H).

\section{Antagonism of slMCb signaling by AgRP}

Next, we investigated whether the human AgRP peptide (83-139) could inhibit slMCa and slMCb signaling. Competition binding curves for the slMCa or slMCb regulated by MRAP2s were shown in Fig. 5. Interestingly, the AgRP neither inhibited nor increased the slMCa signaling regardless of the presence of MRAP2s, 
A

slmca

rlMCa

esMC1R

esMC2R

slMCa

rlMCa

esMC1R

esMC $2 R$

slMCa

rlMCa

esMC1R

esMC2R

slMCa

rIMCa

esMC1R

esMC2R

slMCa

rlMCa

esMC1R

esMC2R

B

slMCb

rlMCb

esMC 3R

esMC4R

esMC5R

$\mathrm{s} \perp \mathrm{MCb}$

rlMCb

esMC 3R

esMC 4R

esMC5R

slMCb

r $1 \mathrm{MCb}$

esMC 3R

esMC4R

esMC5R

slMCb

rlMCb

esMC 3R

esMC 4R

esMC5R

slMCb

$\mathrm{r} 1 \mathrm{MCb}$

esMC 3R

esMC4R

esMC5R

C

SIMRAP2

ESMRAP2

z $I M R A P 2 a$

$\mathrm{z}$ IMRAP $2 \mathrm{~b}$

SIMRAP2

ESMRAP2

$\mathrm{z}$ IMRAP $2 \mathrm{a}$

$z$ fMRAP $2 b$

SIMRAP2

ESMRAP2

$z$ IMRAP $2 a$

$z$ fMRAP $2 b$
... MNLSEALFPNPFVGSPGP DGNGTAVASANRTRFS PCHNFSI PNEVFLTLGIVSLVENALVIAA IARNRNMHS PMYC .... MNLSEALF PNP FVGTSGP D DNGTASASANRTRFS PCHNFSI PTEVFLALG IVSLVENALVIAA IARNRNMHS PMYC .....EDLRLHWLP. . . . . . HGANSSSNMSAVA . . . . . . CQHVSVPEEVFLSLGIVSLVENILVMTAIIKNRNLHSPMHY MSGADTSASPWLAN. . VTTAVMNT SGFMNGSGG . . . . . I ICRQLEI PLEVYL I LGGVGMLENLLVI I AVVNNRNLH S PMYL

FI CSLAVADLLVCLSNAWET I A IA LVHGRHVH I PAP ILQHVDNVFDSF I CI SVVASMCNLLAIAVDRYVT I FYALQYHS I FI CS LAVADLLVCLSNAWET I A IALVH GRHVH I PAR ILQHVDNVF DSF I CI SVVASMCNLLAIAVDRYVT I FYALQYHS I FI CCLAAA DMLVSVSNMVET IVL I LMERGVMVVQNY LLKQ I DNLI DMM I CS SMVS SLS F LGAIAADRYIT I FYALRYHT I

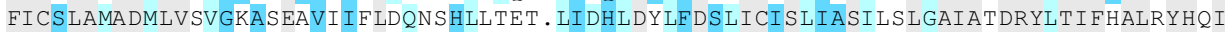

VTMRRAAVVIACVWAACVVSGTLFITYWDHRAVIVCLIALFVTMLVLMASLYAHMFALARSHARRISAQPRS SRQGQQHG VTMRRAAVV IACVWAACVVSGTLF ITYWDHRTVIVCLIALFVTMLVLMASLYAHMFALARS HAQR I SAQPRS SRQ GQQNG MT TRRAVGVMVG IWVVS I TS SA I F IVYSENSAVV I CLIS F F FVMVI FMGALY LHMFT LAR I HAKR I MAQHKKR . . . TL HQ MTVKRAAL I ISALWTFCTFSGSF I IKFNRKNAFPGS LITMYFTTLFVIVSLYVYMFLLARRHAQC IRSLPGQR . . . VHQ

AASLKGAVTLS I LLGVFVFCWAPFFLHLTF I I SCPANPYCCAY IAYF P LYLLL IMINSVIDPL I YAFRSPELRVI IRDTL

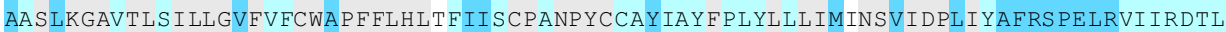
ATSMKGAITLT ILLGVFLICWSPFFLHLILIILCPTNPYCQCFTSHFNMFLILI ICNSVIDPI I . . . . . . . . . . . GT S LKGAI TLT I LLG I F I ICWAP F FL H L I LVLACP SNPYCTCYMS L FQVDL I L I MCNS I I DPL I FAFRSPE LRNT FKKMC

RKCGRGRG. . ANGTR. SSSCCVOVR

RKCGRGRGRGANGTRGS SCCCVQVR

ICFNKQLY . . . . . . . . .

MSY PRAMT F SAAGGVGGVVNNHHQGANHHA GHGNHS GHGNA T GGGHGRPCEQVLIPVEVFL ILGVIS LLEN ILVITA I LK ..... MT F SAGG. VGGVVNNH H HANHQGG. GNHS GH GNA TGGGHGRPCEQVL I PI EVFL ILGVIS LLEN ILVITA I LK

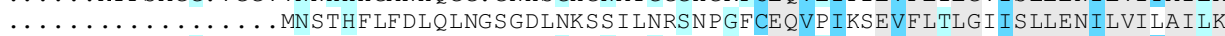
.... MKLLSTPLGS FVIRATEVMPVVT LHFRNOSFAGFTNTNGSHSKGCYEOLLI STEVFLTLGI ISLLENI LVITAI IK $\ldots \ldots \ldots$. . . . MNS TDAHLRRHKWWLRNLSVVDES LNETKGVSGPCEQVTVAVE IFLTLGTVS LLENTLVITAIVK

NKN L H S PMYY F I CS LAVA DMLVSVSNAWE T I IMA LLQNGS LAMQE D T LKQMDN I MDSMI C T SVVASMCS LLA I AVDRYVT NKN L H S PMYY F I CS LAVA DMLVSVSNAWET I IMA LL QNGS LAMQE D T LKOMDN IMDSM I C T SVVASMCS LLA I AVDRYVT NKNL HS PMYFFLCS LAVADMLVSVSNALET TVMALLNNGYLVANDOF I O IMDNVI DS L IC I SLVAS I CNLLVIAIDRYIT NKNL L S PMYFF I CS LAVA DMLVSVSNACE T IT I ALLESRH LLAEDS L I KSMDNVF DSMI CS SLLAS I CS LLA I AVDRY I T NKNLHS PMY LF I CS LAVADLLVSASNAWETVVI ALLNGRH LVVEE SMVKQVDNVLDAMI C I SVVASMCS LSA I AVDRYVT

IFYALRYHN I MTVRRAAS I I GA I WGTC TLCGV I F I VYS DS TAVI ICL I AMF FTMLVLMAS LYVHMFMLARLHAKR I AALP IFYALRYHN IMTVRRAAS I I GA I WGTCTLCGV I F IVYS DSTAVIICL I TMF F TMLVLMAS LYVHMFMLARL HAKR I AALP IFYALRYHS I MTVKRA L LLI IV IW IAC I FCGI I F I I YSNSKTV I I C L I M F F TMLVLMT T LYVHMFMLARLH I KK I AAL P IFYALRYHN I MTVRRAM I I S G I WMA CTGS GI L F IVYSESTMV I I C L I TMF FTML TLMAS LYVHMFMLARL HVKR I AA LP IFYALRYH I MTVKRAA I AIAG I WTFCT SCGIVF I L YSETMAVVVC LVAMFF I MLLLMAS LYI HMF LLARS HVKR I AALP

ASG I IQHKT SMRGA ITLT ILLGVF IVCWAPFFLHL I LIVSCPRSPYCVCYMS HFNLYLVL IMLSSVIDP I IYAFRSHEMR AS G I IQHKT SMRGA I T LT ILLGVF IVCWAP FF LHL I LIVSCPRSPYCVCYMS H FN LY LVL I ML S SV I DP I IYA FRS HEMR VDG IVRPRTCMKGA IT I T ILLG I F I I CWAP FF LHL I LI I SC PKNAYC I CYTS HFNTY L I L IMCNSVIDPMIYAFRS QEMR VNGA I RQA TNMKGA I TVT ILMGVFVVCWAP FFMHL I LM I SC PWNPY CVC FMS H FNMY L I L I MCNSVVDP L I YAFRS QEMR GYNS I HQKA SMKGAVT LT I LL I FVVCWAP FF L H L I LM I S C PVNMY CVC FMS H FN LY L I L I MCNS I I DP L I YAFRS QEMR

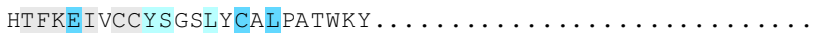

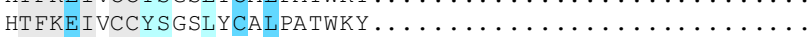

KTFKEIACCYGMNLNSRFSVHRINAAETERTSESSCHCDFGKTSVFNQVALSV

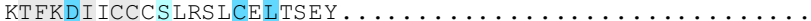

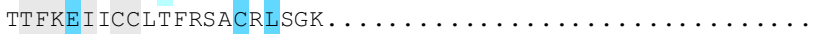

. . . LNGSERASART PGSNRSKEYYWDFEYY.DYEPISFEGLRAHRYS IVIGFWVGIASFVLFMFFILVMLVRSG . . . . . MSENNPVVNKTTHHPGEN . . NDYTWGYEYY.DYGPVSEEGLKAHRYS IV IGFWVGLVVFVI FMF FVLTLLTKTGAPHQEN ... . MPRFQLSNST SVPN . HNYEWSYEYYDDEEPVSEEGLKAHRYS IVIGFWVGLAVFVIFMFFVLTLLTKTGAPHPEA .... MS . . EYSN.RSQAG . ADYEWHYEYYEDEEPVSFEGLRANRYS IVIGFWVGLAVFVI FMF FVLTLLTKTGAPHPEM

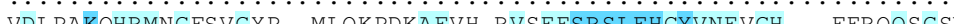
VDLPAKQHRMNGFSVGYP...MLQKPDKAFVH. RVSEESRSLFHCYVNEVGH . . . FERQQSGSRISGPKNEDLVTHEKEGE AE PYEKRMRL T S CA D GL GRQRET DGRTGLSR. P LLEESRS LF HCY I NEEEREGGRAAT DAGALTHGRSG I GNSRGQVEEV CDASMKPHVLIGCELEVG . . . . . GS LAFS LPPLPDQSRSLFHFYI HKEER . .VKTHKDA . . VIGR. GMHCGRGNAE . .

S. . . . . DILVEPWNCLAKFDIPNFVNSDQSSSLAED DLLMCDQPIVLENKPIS . . . . AHNIHQNSD

GLVVQNMVLESRAEREAALLAHFN IPNFVNSELNSALGDEDLLLGDPP I IMEEAR . . . . . . PRCTHH I ID

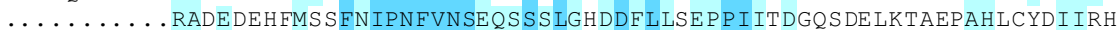

\section{Figure 1}

Sequence alignments of sea lamprey MRAP2 and MCRs. (A and B) Sequence alignment of MCRs from sea lamprey(sl), river lamprey(rl) and elephant shark(es). (C) Sequences alignment of MRAP2s from sea lamprey(sl), elephant shark(es) and zebrafish(zf).

https://ec.bioscientifica.com https://doi.org/10.1530/EC-19-0019
(C) 2019 The authors Published by Bioscientifica Ltd

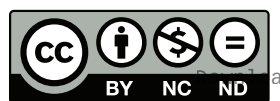

This work is licensed under a Creative Commons Attribution-NonCommercial-NoDerivatives 4.0 Internationab ticense.ifica com at $04 / 26 / 2023 \quad 10: 00: 13 A M$ 
A

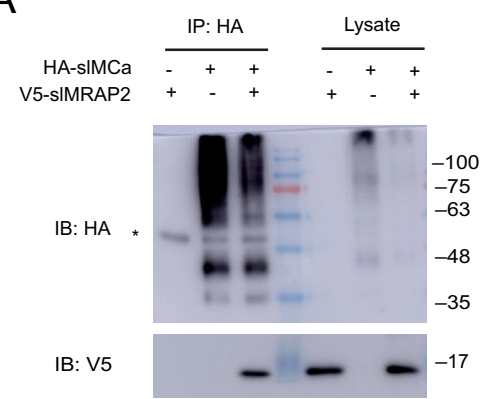

C

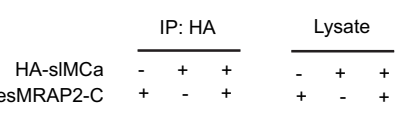

V5-esMRAP2-C

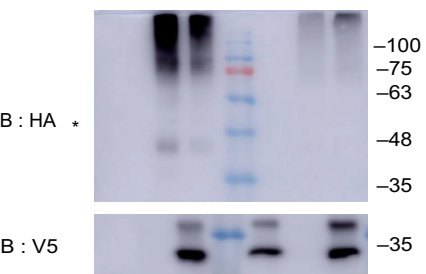

E

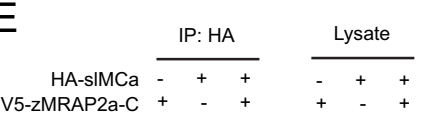

IB : HA

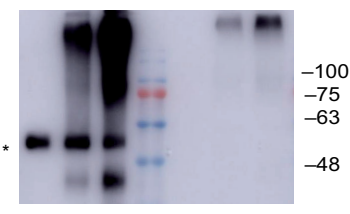

IB : V5

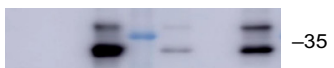

G

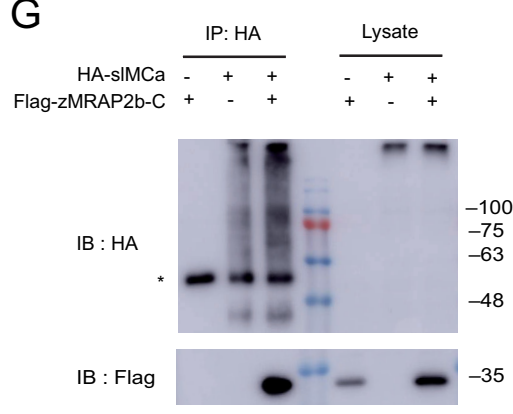

I

\begin{tabular}{r|c|c|c|}
\cline { 2 - 4 } SIMRAP2 & $\mathrm{N}$ & TM & $\mathrm{C}$ \\
\cline { 2 - 4 } ESMRAP2-C & $\mathrm{N}$ & TM & $\mathrm{C}$ \\
\cline { 2 - 4 } ZMRAP2a-C & $\mathrm{N}$ & $\mathrm{TM}$ & $\mathrm{C}$ \\
\cline { 2 - 4 } ZMRAP2b-C & $\mathrm{N}$ & TM & $\mathrm{C}$ \\
\cline { 2 - 4 } & & &
\end{tabular}

B

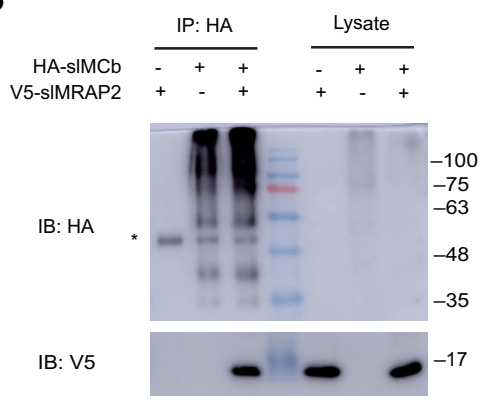

D

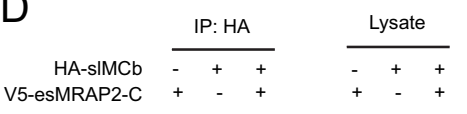

5-esMRAP2-C

IB : HA

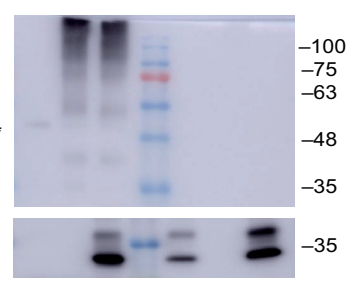

$\mathrm{F}$

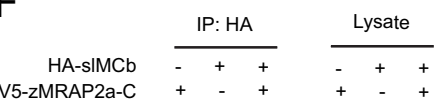

IB : HA

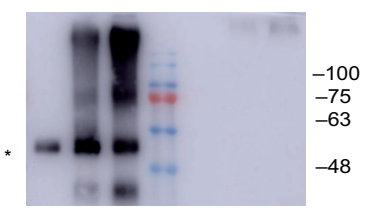

IB : V5

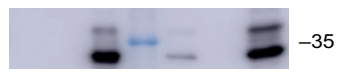

$\mathrm{H}$

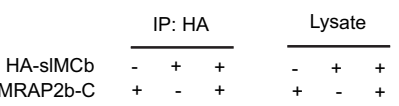

IB : HA

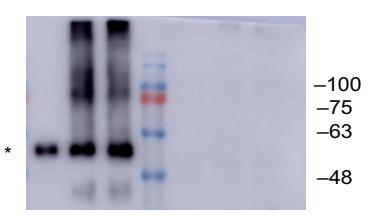

IB : Flag

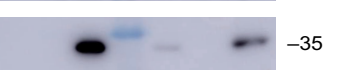

\section{Figure 2}

Interaction of MRAP2 proteins with sIMCa or sIMCb. Co-IP of sIMCa or sIMCb with four types of MRAP2 proteins: (A and B) sIMRAP2, ( $C$ and D) esMRAP2-C, ( $E$ and $F$ ) zMRAP2a-C and ( $G$ and $H$ ). * IgG heavy chain. (I) Schematic diagram of four MRAP2 plasmids. $\mathrm{N}$ terminus and TM domain of esMRAP2-C, zMRAP2a-C and $z$ MRAP2b-C originate from SIMRAP2, and the carboxyl terminus is captured from esMRAP2, zMRAP2a or ZMRAP2b. 
indicating the lack of antagonism of AgRP on slMCa (Fig. 5A, C, E and G). However, AgRP could clearly inhibit the slMCb signaling (Fig. 5B, D, F and $\mathrm{H}$ ) with the fact that the $\mathrm{IC}_{50}$ showed no significant difference when co-expressed with four types of MRAP2 proteins (Table 3).

\section{Dimerization of sea lamprey MRAP2 and MCRs}

To determine whether slMRAP2 could form an antiparallel homodimer, such as those of mouse or human MRAP2 proteins, a complementary YFP luminescent
A

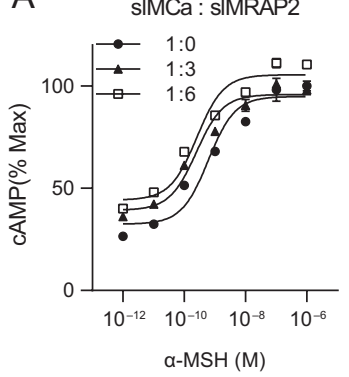

$\mathrm{E}$

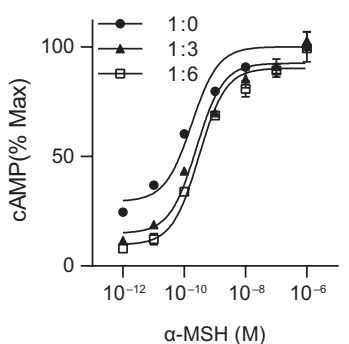

B

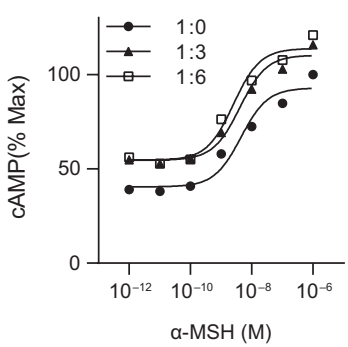

$\mathrm{F}$

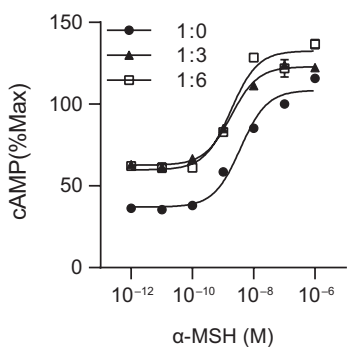

C

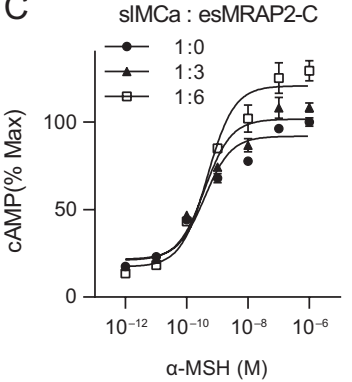

G

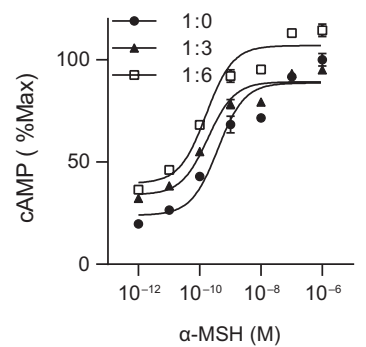

D SIMCb : esMRAP2-C

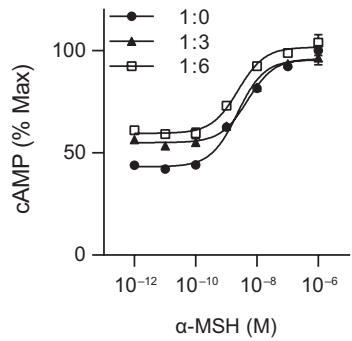

$\mathrm{H}$

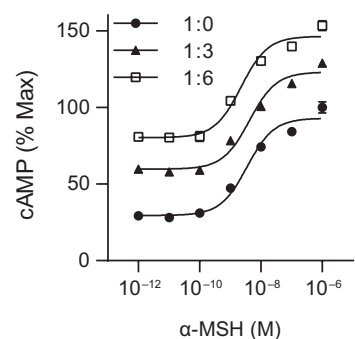

Figure 3

Modulation of sIMCa and sIMCb signaling by MRAP2s. $\alpha$-MSH stimulated CAMP cascade of sIMCa or sIMCb is modulated in the presence of (A and B) SIMRAP2, (C and D) esMRAP2-C, (E and F) zMRAP2a-C and ( $G$ and H) zMRAP2b-C.

Table 2 Statistical analysis of Fig. 3.

\begin{tabular}{ll}
\hline \multicolumn{2}{l}{ Data analysis } \\
\hline 3A & SIMCa: sIMRAP2 \\
3B & SIMCb: sIMRAP2 \\
3C & sIMCa: esMRAP2-C \\
3D & SIMCb: esMRAP2-C \\
3E & SIMCa: zMRAP2a-C \\
3F & sIMCb: ZMRAP2a-C \\
3G & SIMCa: ZMRAP2b-C \\
3H & SIMCb: ZMRAP2b-C \\
\hline
\end{tabular}

\begin{tabular}{cccc}
\hline & & LogEC $_{\mathbf{5 0}}$ \\
\hline $1: 0$ & & $1: 3$ \\
\cline { 1 - 1 }$-9.22 \pm 0.30$ & & $-9.61 \pm 0.25$ \\
$-8.35 \pm 0.28$ & & $-8.20 \pm 0.39$ \\
$-9.42 \pm 0.28$ & & $-9.42 \pm 0.28$ \\
$-8.64 \pm 0.18$ & & $-8.13 \pm 0.36$ \\
$-9.76 \pm 0.34$ & & $-9.60 \pm 0.25$ \\
$-8.44 \pm 0.20$ & & $-8.63 \pm 0.23$ \\
$-9.41 \pm 0.35$ & & $-9.49 \pm 0.48$ \\
$-8.46 \pm 0.21$ & & $-8.18 \pm 0.39$ \\
\hline
\end{tabular}

\begin{tabular}{c}
$1: 6$ \\
\hline$-9.59 \pm 0.27$ \\
$-8.60 \pm 0.23$ \\
$-9.324 \pm 0.27$ \\
$-8.62 \pm 0.22$ \\
$-9.52 \pm 0.20$ \\
$-8.74 \pm 0.24$ \\
$-9.79 \pm 0.27$ \\
$-8.65 \pm 0.22$
\end{tabular}

\begin{tabular}{|c|c|c|}
\hline \multicolumn{3}{|c|}{$P$ value for Vmax comparison } \\
\hline $1: 0$ vs $1: 3$ & $1: 0$ vs $1: 6$ & $1: 3$ vs $1: 6$ \\
\hline 0.5695 & $<0.0001$ & 0.0001 \\
\hline$<0.0001$ & $<0.0001$ & 0.0289 \\
\hline 0.0527 & $<0.0001$ & 0.0003 \\
\hline 0.3386 & 0.0258 & 0.0103 \\
\hline$<0.0001$ & $<0.0001$ & 0.6048 \\
\hline$<0.0001$ & $<0.0001$ & $<0.0001$ \\
\hline 0.155 & $<0.0001$ & $<0.0001$ \\
\hline$<0.0001$ & $<0.0001$ & $<0.0001$ \\
\hline
\end{tabular}

Two-way ANOVA with Tukey post-test was applied in the statistical analysis.

Table 3 Statistical analysis of Fig. 5.

\begin{tabular}{|c|c|c|c|c|}
\hline \multirow{2}{*}{\multicolumn{2}{|c|}{ Data analysis }} & \multicolumn{3}{|c|}{$\log C_{50}$} \\
\hline & & \multirow{2}{*}{$\begin{array}{c}1: 0 \\
-9.22 \pm 0.63\end{array}$} & \multirow{2}{*}{$\begin{array}{c}1: 3 \\
-9.11 \pm 0.42\end{array}$} & \multirow{2}{*}{$\begin{array}{c}1: 6 \\
9.23 \pm 0.26\end{array}$} \\
\hline $5 B$ & sIMCb: sIMRAP2 & & & \\
\hline $5 D$ & sIMCb: esMRAP2-C & $-9.17 \pm 0.28$ & $-9.36 \pm 0.47$ & $9.18 \pm 0.65$ \\
\hline $5 F$ & sIMCb: zMRAP2a-C & $-9.24 \pm 0.45$ & $-9.38 \pm 0.64$ & $9.39 \pm 0.55$ \\
\hline $5 \mathrm{H}$ & sIMCb: zMRAP2b-C & $-9.32 \pm 0.42$ & $-9.26 \pm 0.62$ & $8.73 \pm 0.63$ \\
\hline
\end{tabular}

\begin{tabular}{|c|c|c|}
\hline \multicolumn{3}{|c|}{$P$ value for Vmax comparison } \\
\hline $1: 0$ vs $1: 3$ & $1: 0$ vs $1: 6$ & $1: 3$ vs $1: 6$ \\
\hline$<0.0001$ & $<0.0001$ & 0.0518 \\
\hline$<0.0001$ & $<0.0001$ & 0.005 \\
\hline$<0.0001$ & $<0.0001$ & 0.0127 \\
\hline$<0.0001$ & $<0.0001$ & $<0.0001$ \\
\hline
\end{tabular}

Two-way ANOVA with Tukey post-test was applied in the statistical analysis.

https://ec.bioscientifica.com https://doi.org/10.1530/EC-19-0019 (c) 2019 The authors Published by Bioscientifica Ltd
This work is licensed under a Creative Commons Attribution-NonCommercial-NoDerivatives 4.0 elnternationad ticense.ifica.com at 04/26/2023 10:00:13AM 
A SIMCa : SIMRAP2

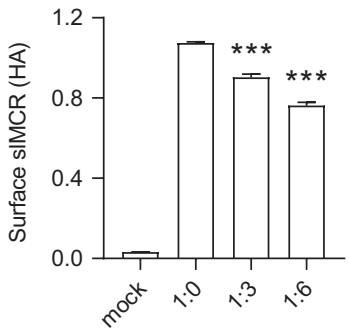

E SIMCa: zMRAP2a-C

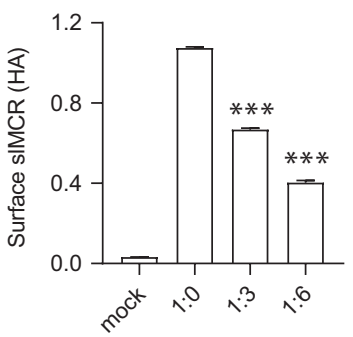

B SIMCb : SIMRAP2

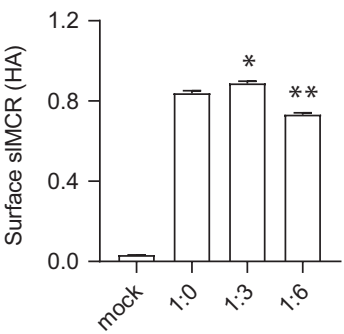

F

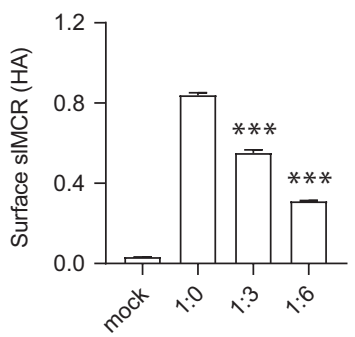

C
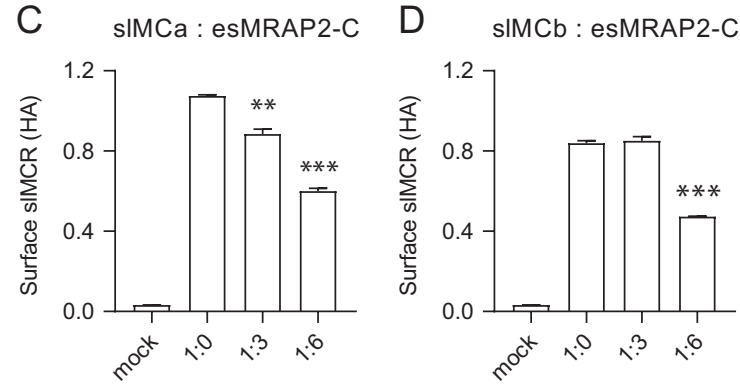

G SIMCa : zMRAP2b-C

H SIMCb : ZMRAP2b-C
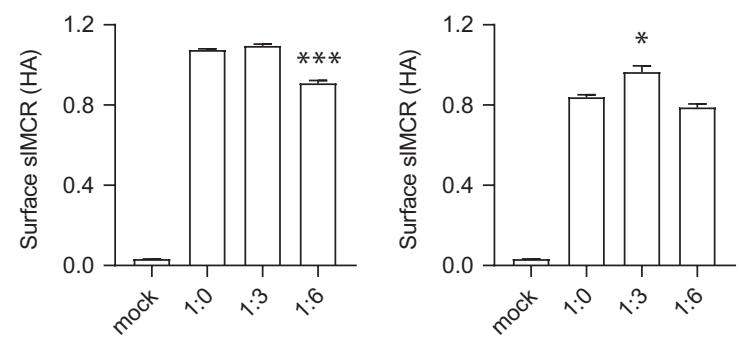

Figure 4

Surface expression regulation of sIMCa and sIMCb by MRAP2s. Surface expression of sIMCa or sIMCb is modulated by (A and B) sIMRAP2, (C and D) esMRAP2-C, (E and F) zMRAP2a-C and (G and H) zMRAP2b-C. $* P<0.05 ; * \star P<0.01 ; * \star \star P<0.001$.

assay was conducted. A schematic representation of configurations in which slMRAP2 molecules fused with YFP fragments on the cell membrane is shown in Fig. $6 \mathrm{~A}$, and the interaction of slMRAP2 homodimers were proved by Co-IP as shown in Fig. 6B. In this study, we also checked the dimerization of slMCa and slMCb. Clear YFP fluorescence on the plasma membrane (Fig. 6C, D and E) and Co-IP results (Fig. 6F, G and H) provided strong evidence that slMCa and slMCb could form either homodimer or heterodimer in vitro.
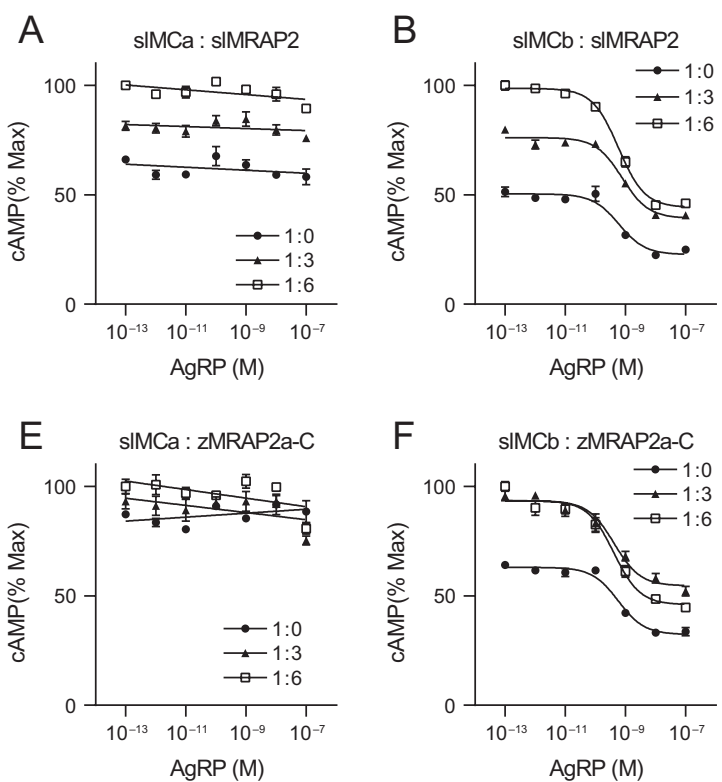

F $\quad$ SIMCb : ZMRAP2a-C

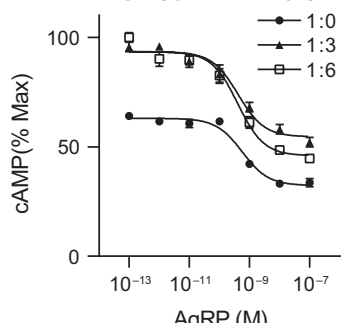

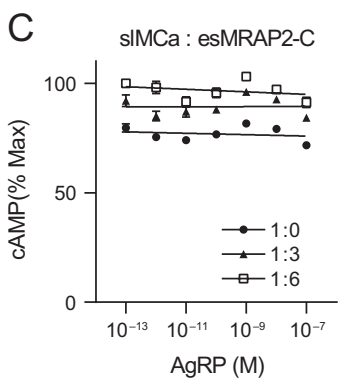
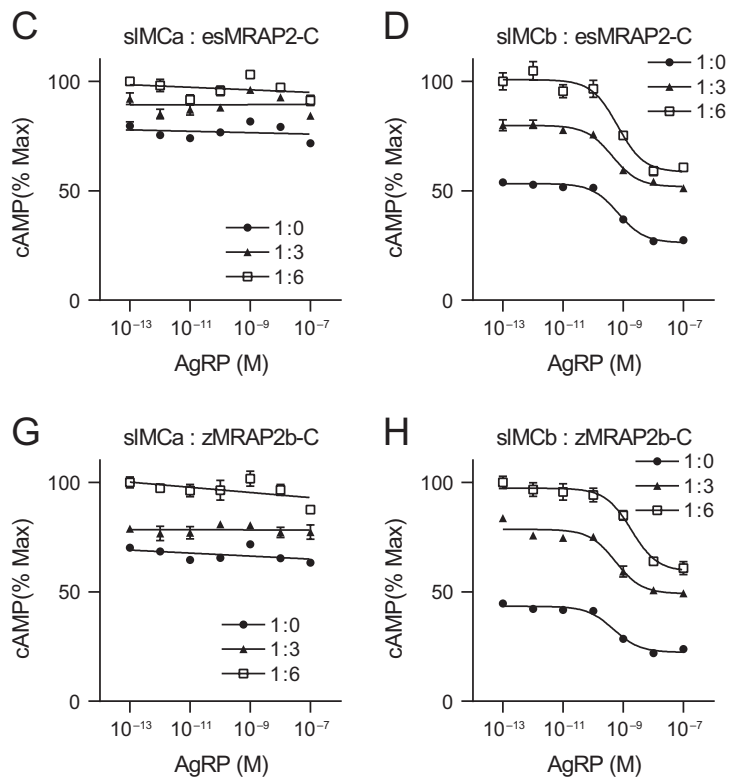

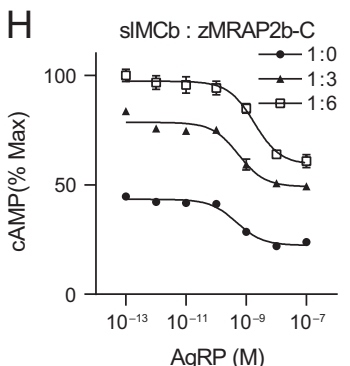

Figure 5

AGRP competitively inhibits sIMCb not sIMCa signaling. Competition binding inhibition curves for the sIMCa or sIMCb regulated by (A and B) sIMRAP2, ( $C$ and D) esMRAP2-C, (E and F) zMRAP2a-C and ( $G$ and H) zMRAP2b-C.

https://ec.bioscientifica.com https://doi.org/10.1530/EC-19-0019 (c) 2019 The authors Published by Bioscientifica Ltd

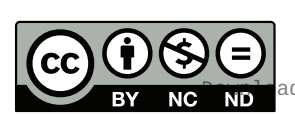

This work is licensed under a Creative Commons Attribution-NonCommercial-NoDerivatives 4.0 delnternationad bicense.ifica.com at 04/26/2023 10:00:13AM 
A

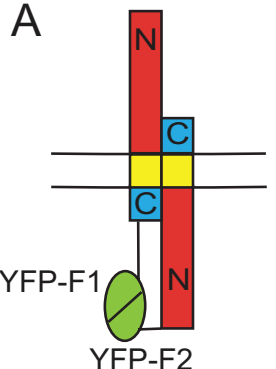

C
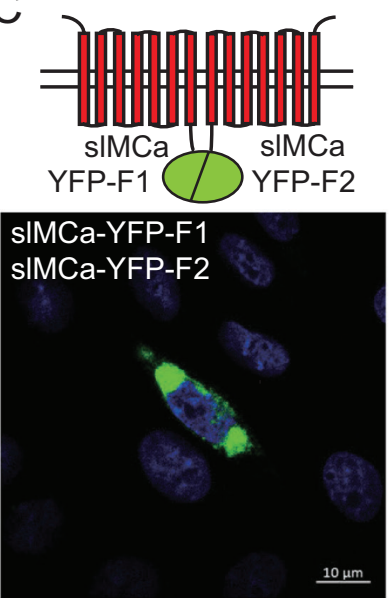

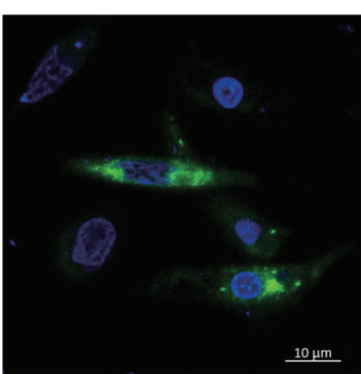

$\mathrm{D}$
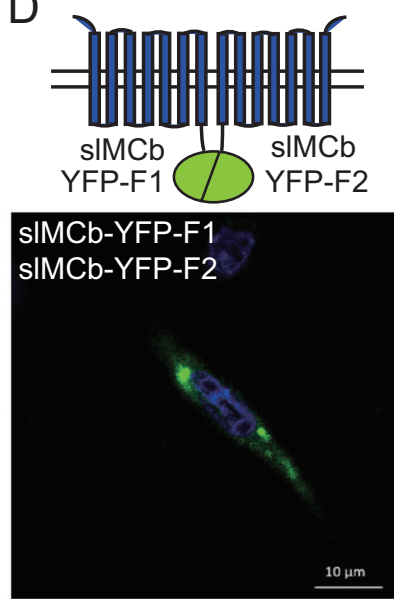

B

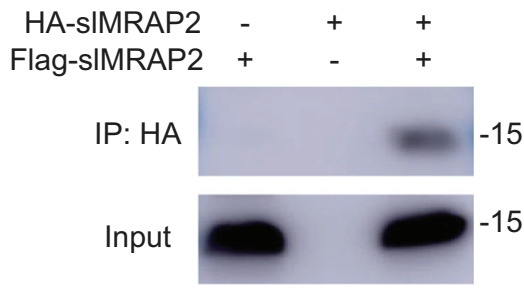

IB: Flag
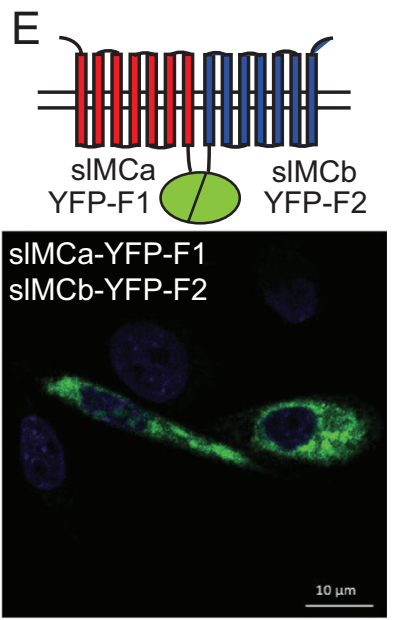

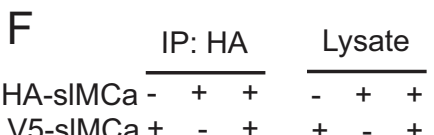

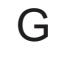

G $\frac{\text { IP: HA }}{\text { HA-sIMCb }-++}$

$\frac{\text { Lysate }}{-++}$

H $\frac{\text { IP: HA }}{\text { HA-sIMCa }-++} \frac{\text { Lysate }}{-}+++$
V5-sIMCb $+-++\quad+$

IB : HA
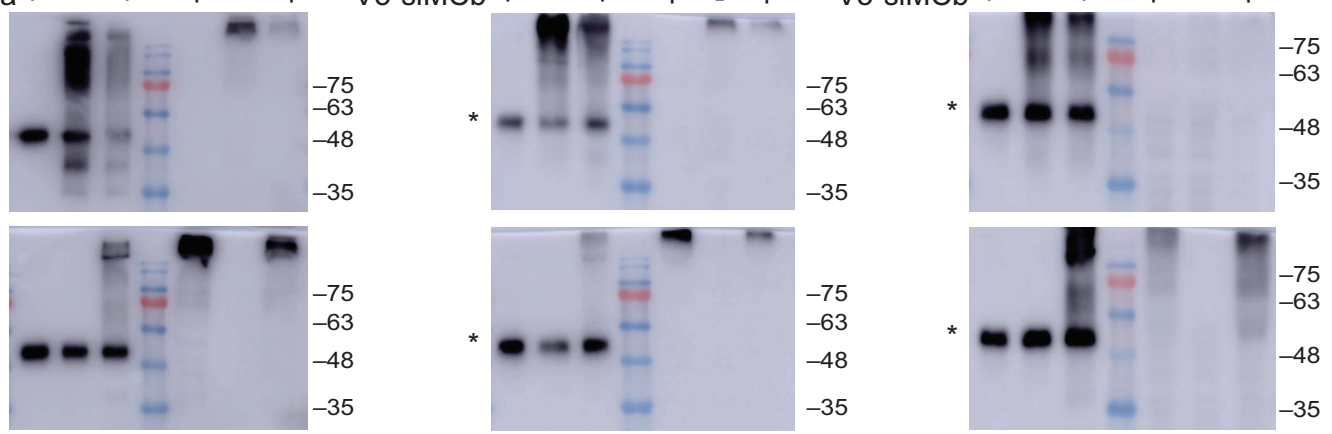

Figure 6

Dimerization of sea lamprey MRAP2, MCa and MCb. (A) YFP fluorescence emitted by sIMRAP2 antiparallel homodimers. Scale bar: $10 \mu$ m. (B) Co-IP of sIMRAP2 homodimers. (C, D and E) YFP fluorescence emitted by sIMCR homo- and heterodimers. Scale bar: $10 \mu \mathrm{m}$. (F, G and H) Co-IP of sIMCRS homo- and heterodimers. *IgG heavy chain.

\section{Discussion}

In this study, we focused on whether the regulatory effect of MRAP2 on MCRs existed in the sea lamprey, even though no ligand had been identified and slMRAP2 and slMCRs were greatly different from that of mammals. We first compared slMCa, slMCb and slMRAP2 protein sequences with orthologs from river lamprey, elephant shark and zebrafish. Alignment suggested that slMCa and slMCb were highly conserved with rlMCa and rlMCb, respectively (identity $>88 \%$ ). For the ancestral slMRAP2, previous studies had revealed a partial protein sequence $(22,25)$. The partial slMRAP2 was aligned with many other MRAP2 subtypes and reported to be highly conserved at the 
TM domain (23). However, we found a stop codon located at the third codon behind the TM domain of sIMRAP2. We speculated that the carboxyl terminus of slMRAP2 might be naturally shorter than other MRAP2 orthologs. To verify the regulatory function of the short sIMRAP2 on slMCRs, we constructed three other MRAP2s with the carboxyl terminus from several other species. Like those of mouse and human MRAP2 $(12,13)$, slMRAP2 could form a protein complex with both slMCa and slMCb. This result suggested that lack of the carboxyl terminus of slMRAP2 had no effect on its binding to slMCRs. However, the carboxyl terminus of MRAP2 seemed to affect the glycosylation of MRAP2. Co-IP results showed that similar to hMRAP2 (12), two MRAP2 bands were seen for esMRAP2-C and zMRAP2a-C, whereas sIMRAP2 and zMRAP2b-C only had one band, indicating the requirement for an unknown key motif within the carboxyl terminus for the glycosylation of MRAP2 protein.

We demonstrated, for the first time, that the most ancient known MRAP2 interacted with MCRs. Therefore, it was interesting to see whether the sIMRAP2 could affect the pharmacological features of melanocortin receptors. As shown, in common with esMRAP2-C and zMRAP2b-C, slMRAP2 could enhance slMCa or slMCb signaling by elevating their constitutive activities and $\alpha$-MSH-induced agonism. Mouse MRAP2 was reported to enhance cAMP signaling through MC3R and MC4R (14). However, an exception was observed, in that zMRAP2a-C inhibited the slMCa signaling and increased that of slMCb. This difference might be caused by the different regulatory effects of MRAP2a and MRAP2b. In zebrafish, zMRAP2a blunted MC4R signaling, while zMRAP2b decreased the constitutive activity but promoted the stimulating activity of MC4R (15). To elucidate the mechanism by which slMRAP2 regulates slMCa and slMCb, we next performed ELISA assays and ligand competition-binding assays. The general trends of slMCa and slMCb surface expression were attenuated with a high concentration of sIMRAP2, which were in line with esMRAP2-C and zMRAP2a-C. However, zMRAP2b-C showed no effect on the surface expression of slMCb. Our results are consistent with previous work by Webb et al., in that the carboxyl terminus was not required for the interaction or surface trafficking of the MC2R (26), although the carboxyl terminus of zebrafish MRAP2a slightly altered the regulatory capacity of slMRAP2. Taken together, slMRAP2 could boost slMCRs activity without increasing the surface expression of slMCRs. Interestingly, we also found that AgRP, a specific antagonist to MC3R and MC4R (1), could not compete with $\alpha$-MSH on the slMCa signaling, suggesting that slMCa was more similar to MC1R and MC2R, whereas slMCb was more similar to MC3R and $\operatorname{MC} 4 \mathrm{R}(20,21,22)$.

MRAPs and MCRs have been reported to form homodimers in vitro $(10,27,28,29,30)$. Our recent work demonstrated that zebrafish MC5Ra and MC5Rb could form homo- and heterodimers, which could be disrupted by MRAP2a or MRAP2b proteins (24). Therefore, we also conducted YFP luminescent assays and identified the formation of antiparallel homodimers of slMRAP2. Sebag et al. reported that amino acids 31-37 of human MRAP1 were required for its dual topology, which are located just before the TM domain (27). This motif in MRAP1 was found to be highly conserved in the MRAP2 of many species including sea lamprey. In accordance with previous reports $(6,7)$, slMCa and slMCb were observed to form homodimers and heterodimers as predicted and confirmed by YFP luminescent and Co-IP experiments.

In conclusion, here we have provided the first evidence that the ancient slMRAP2 lacking carboxyl terminus was fully functional and could modulate the signaling of two slMCRs in the form of antiparallel dimers. We also identified the homo- and hetero-dimerization of slMCa and slMCb. This study provides a better insight of the emerging melanocortin system in the agnathans, elucidated the presence and functional modulation of the melanocortin receptor by ancient accessory proteins, which could help us to further investigate the evolutionary perspective of the melanocortin system in the future.

\section{Declaration of interest}

The authors declare that there is no conflict of interest that could be perceived as prejudicing the impartiality of the research reported.

\section{Funding}

The work was supported by grants from National Key Research and Development Program of China (Grant No. 2017YFA0103902). The National Natural Science Foundation of China (Grant No. 81570760 and 31771283).

\section{References}

1 Cone RD. Studies on the physiological functions of the melanocortin system. Endocrine Reviews 200627 736-749. (https://doi.org/10.1210/ er.2006-0034)

2 Blanchard SG, Harris CO, Ittoop OR, Nichols JS, Parks DJ, Truesdale AT \& Wilkison WO. Agouti antagonism of melanocortin binding and action in the B16F10 murine melanoma cell line. Biochemistry 199534 10406-10411. (https://doi.org/10.1021/ bi00033a012)

3 Ollmann MM, Wilson BD, Yang YK, Kerns JA, Chen Y, Gantz I \& Barsh GS. Antagonism of central melanocortin receptors in vitro and in vivo by agouti-related protein. Science 1997278 135-138. (https:// doi.org/10.1126/science.278.5335.135) 
4 Dores RM, Lecaude S, Bauer D \& Danielson PB. Analyzing the evolution of the opioid/orphanin gene family. Mass Spectrometry Reviews 200221 220-243. (https://doi.org/10.1002/mas.10029)

5 Mandrika I, Petrovska R \& Wikberg J. Melanocortin receptors form constitutive homo- and heterodimers. Biochemical and Biophysical Research Communications 2005326 349-354. (https://doi. org/10.1016/j.bbrc.2004.11.036)

6 Rediger A, Piechowski CL, Habegger K, Gruters A, Krude H, Tschop MH Kleinau G \& Biebermann H. MC4R dimerization in the paraventricular nucleus and GHSR/MC3R heterodimerization in the arcuate nucleus: is there relevance for body weight regulation? Neuroendocrinology 201295 277-288. (https://doi.org/10.1159/000334903)

7 Kobayashi Y, Hamamoto A, Takahashi A \& Saito Y. Dimerization of melanocortin receptor 1 (MC1R) and MC5R creates a ligand-dependent signal modulation: potential participation in physiological color change in the flounder. General and Comparative Endocrinology 2016 230-231 103-109. (https://doi.org/10.1016/j.ygcen.2016.04.008)

8 Cortes R, Navarro S, Agulleiro MJ, Guillot R, Garcia-Herranz V, Sanchez E \& Cerda-Reverter JM. Evolution of the melanocortin system. General and Comparative Endocrinology 2014209 3-10. (https://doi.org/10.1016/j.ygcen.2014.04.005)

9 Metherell LA, Chapple JP, Cooray S, David A, Becker C, Ruschendorf F, Naville D, Begeot M, Khoo B, Nurnberg P, et al. Mutations in MRAP, encoding a new interacting partner of the ACTH receptor, cause familial glucocorticoid deficiency type 2 . Nature Genetics 200537 166-170. (https://doi.org/10.1038/ng1501)

10 Sebag JA \& Hinkle PM. Melanocortin-2 receptor accessory protein MRAP forms antiparallel homodimers. PNAS 2007104 20244-20249. (https://doi.org/10.1073/pnas.0708916105)

11 Sebag JA \& Hinkle PM. Opposite effects of the melanocortin-2 (MC2) receptor accessory protein MRAP on MC2 and MC5 receptor dimerization and trafficking. Journal of Biological Chemistry 2009284 22641-22648. (https://doi.org/10.1074/jbc.M109.022400)

12 Chan LF, Webb TR, Chung TT, Meimaridou E, Cooray SN, Guasti L, Chapple JP, Egertova M, Elphick MR, Cheetham ME, et al. MRAP and MRAP2 are bidirectional regulators of the melanocortin receptor family. PNAS 2009106 6146-6151. (https://doi.org/10.1073/ pnas.0809918106)

13 Sebag JA \& Hinkle PM. Regulation of G protein-coupled receptor signaling: specific dominant-negative effects of melanocortin 2 receptor accessory protein 2. Science Signaling 20103 ra28. (https:// doi.org/10.1126/scisignal.2000593)

14 Asai M, Ramachandrappa S, Joachim M, Shen Y, Zhang R, Nuthalapati N, Ramanathan V, Strochlic DE, Ferket P, Linhart K, et al. Loss of function of the melanocortin 2 receptor accessory protein 2 is associated with mammalian obesity. Science $2013341275-278$. (https://doi.org/10.1126/science.1233000)

15 Sebag JA, Zhang C, Hinkle PM, Bradshaw AM \& Cone RD. Developmental control of the melanocortin- 4 receptor by MRAP2 proteins in zebrafish. Science 2013341 278-281. (https://doi. org/10.1126/science.1232995)

16 Liu T, Elmquist JK \& Williams KW. Mrap2: an accessory protein linked to obesity. Cell Metabolism 201318 309-311. (https://doi. org/10.1016/j.cmet.2013.08.016)

17 Logan DW, Bryson-Richardson RJ, Pagan KE, Taylor MS, Currie PD $\&$ Jackson IJ. The structure and evolution of the melanocortin and MCH receptors in fish and mammals. Genomics 200381 184-191. (https://doi.org/10.1016/S0888-7543(02)00037-X)

18 Klovins J, Haitina T, Fridmanis D, Kilianova Z, Kapa I, Fredriksson R, Gallo-Payet N \& Schioth HB. The melanocortin system in Fugu: determination of POMC/AGRP/MCR gene repertoire and synteny, as well as pharmacology and anatomical distribution of the MCRs. Molecular Biology and Evolution 200421 563-579. (https://doi. org/10.1093/molbev/msh050)

19 Green SA \& Bronner ME. The lamprey: a jawless vertebrate model system for examining origin of the neural crest and other vertebrate traits. Differentiation 201487 44-51. (https://doi.org/10.1016/j. diff.2014.02.001)

20 Haitina T, Klovins J, Takahashi A, Lowgren M, Ringholm A, Enberg J, Kawauchi H, Larson ET, Fredriksson R \& Schioth HB. Functional characterization of two melanocortin (MC) receptors in lamprey showing orthology to the MC1 and MC4 receptor subtypes. BMC Evolutionary Biology 20077 101. (https://doi.org/10.1186/1471-21487-101)

21 Baron A, Veo K, Angleson J \& Dores RM. Modeling the evolution of the MC2R and MC5R genes: studies on the cartilaginous fish, Heterondotus francisci. General and Comparative Endocrinology 2009 161 13-19. (https://doi.org/10.1016/j.ygcen.2008.11.026)

22 Vastermark $\AA$ \& Schioth HB. The early origin of melanocortin receptors, agouti-related peptide, agouti signalling peptide, and melanocortin receptor-accessory proteins, with emphasis on pufferfishes, elephant shark, lampreys, and amphioxus. European Journal of Pharmacology 2011660 61-69. (https://doi.org/10.1016/j. ejphar.2010.10.106)

23 Valsalan R, Krishnan A, Almén MS, Fredriksson R \& Schiöth HB. Early vertebrate origin of melanocortin 2 receptor accessory proteins (MRAPs). General and Comparative Endocrinology 2013188 123-132. (https://doi.org/10.1016/j.ygcen.2013.01.004)

24 Zhu M, Wang M, Chen Y \& Zhang C. Pharmacological modulation of two melanocortin-5 receptors by MRAP2 proteins in zebrafish. Journal of Molecular Endocrinology 201962 27-36. (https://doi. org/10.1530/JME-18-0104)

25 Dores RM. Hypothesis and theory: revisiting views on the co-evolution of the melanocortin receptors and the accessory proteins, MRAP1 and MRAP2. Frontiers in Endocrinology 2016779 (https://doi.org/10.3389/fendo.2016.00079)

26 Webb TR, Chan L, Cooray SN, Cheetham ME, Chapple JP \& Clark AJL. Distinct melanocortin 2 receptor accessory protein domains are required for melanocortin 2 receptor interaction and promotion of receptor trafficking. Endocrinology 2009150 720-726. (https://doi.org/10.1210/en.2008-0941)

27 Sebag JA \& Hinkle PM. Regions of melanocortin 2 (MC2) receptor accessory protein necessary for dual topology and $\mathrm{MC} 2$ receptor trafficking and signaling. Journal of Biological Chemistry 2009284 610-618. (https://doi.org/10.1074/jbc.M804413200)

28 Nickolls SA \& Maki RA. Dimerization of the melanocortin 4 receptor: a study using bioluminescence resonance energy transfer. Peptides 200627 380-387. (https://doi.org/10.1016/j. peptides.2004.12.037)

29 Sanchez-Laorden BL, Sanchez-Mas J, Martinez-Alonso E, MartinezMenarguez JA, Garcia-Borron JC \& Jimenez-Cervantes C. Dimerization of the human melanocortin 1 receptor: functional consequences and dominant-negative effects. Journal of Investigative Dermatology 2006 126 172-181. (https://doi.org/10.1038/sj.jid.5700036)

30 Cooray SN, Almiro Do Vale I, Leung KY, Webb TR, Chapple JP, Egertova M, Cheetham ME, Elphick MR \& Clark AJL. The melanocortin 2 receptor accessory protein exists as a homodimer and is essential for the function of the melanocortin 2 receptor in the mouse y1 cell line. Endocrinology 2008149 1935-1941. (https://doi. org/10.1210/en.2007-1463) https://ec.bioscientifica.com https://doi.org/10.1530/EC-19-0019
(C) 2019 The authors Published by Bioscientifica Ltd
Received in final form 14 January 2019

Accepted 11 March 2019

Accepted Preprint published online 11 March 2019 